\title{
Determination and Evaluation of the Self-Compassion Levels of the Students Studying in the Sport Sciences Faculties of Universities
}

\author{
Taner Yilmaz, Elif Top and Mustafa Akil \\ Faculty of Sport Sciences, Usak University, Usak 64000, Turkey
}

\begin{abstract}
The present study has been conducted in order to determine the self-compassion levels of the students studying in various departments of the faculties of sports sciences and performing sports, and thus to find out whether certain variables such as their branch, department and families have an effect on their self-compassion levels. The "Self-compassion Scale" was used as the data collection tool in the study. In the present study, when the self-compassion levels of the students of the faculties of sports sciences were evaluated by various variables, it was found that the self-compassion levels of the students of Mugla University were significantly higher than those of the students of Ankara University, that the self-compassion levels of the students studying in the department of teaching were higher than those of the students studying in the department of coaching, and that the self-compassion levels of the students performing the branch of football were significantly higher than those of the students performing the branch of volleyball. When the students were compared based on the cities they live, it was found that the students living in the province of Mugla had significantly higher levels of self-compassion comparing to the students living in the province Ankara. Consequently, it was determined that the self-compassion levels of the students studying in various departments of the faculties of sports sciences were moderate, and that the differences in the province, department and the sports branch had an effect on the levels of self-compassion.
\end{abstract}

Key words: Self-compassion, exercise, physical education, students.

\section{Introduction}

Self-compassion is considered to be connected with positive mental state, satisfaction from life and lower levels of anxiety, and it is defined as not criticizing oneself in the face of negative events encountered by the individual, approaching to such events in an understanding manner and seeing these events as a part of one's experience at the end [1]. Studies have suggested that self-compassion correlates with the academic success and psychological health and has a calming effect in the face of negative life events and distressing situations [2]. Education is accepted to be an important instrument for changing attitudes. This is an important factor in terms of educators and students

Corresponding author: Elif TOP, Ph.D., research fields: physical activity, physical education and sport, adapted physical education. knowing how to evaluate their attitudes in the face of their courses and other events in their lives and in terms of improving the quality of the education [3]. Sport is a combination of systematic physical movements. Having distinctive rules, sports can contribute to the personality and mental development of individuals, their harmony to the society and increased efficiency in their professional life, as well as their physical development [4]. Besides helping individuals in gaining the habit of taking exercise and supporting their psychomotor development, exercise programs also help people in terms of making them individuals who feel psychologically well, who are self-confident and satisfied with their physical appearance and who are disciplined by means of the processes of thinking and feeling they go through [5]. The studies conducted on young adults and adolescents have revealed that self-compassion 
strongly correlates with the state of wellness both in adolescents and young adults. Family and cognitive factors are shown among the determinants of the variations in self-compassion among adolescents and young adults. When the results obtained in this regard are examined, it seems that the negative self-perception of the adolescents with low levels of self-compassion can result in breakdowns. Consequently, self-compassion is based on the family, the cognitive factors and the connections in the state of wellbeing. The examinations have shown that the young people with low levels of self-compassion have a negative perception of themselves and this may result in a breakdown [6]. Along their lives, people experience feelings such as failure and sorrow. In order to be able to cope with such negative feelings, they need to calm down, to relax and deal with these negative feelings without getting harmed. Individuals need to improve their self-compassion attitudes in order to be able to cope with such negative feelings [7].

The present study aims to determine the self-compassion levels of the students studying in various departments of the faculties of sports sciences and performing sports, and whether the variables such as the branch of sports they practice, the university department they study in and their families have an effect on their levels of self-compassion.

\section{Materials and Method}

\subsection{Study Group}

The study has been conducted in accordance with the general screening model. The self-compassion levels were determined to be the dependent variable of the study, while the demographical information was determined to be the independent variable. The population of the study comprises the students studying in various departments of the Faculties of Sports Sciences. The study group was determined by means of the random cluster sampling method. The data collection group of the study comprised the university students studying in the teaching, sports management and coaching departments in the provinces of Konya, Usak, Ankara, Burdur, Adana and Mugla. A total of 393 students, 160 (40.71\%) of which female and 233 (59.29\%) male, and 65 (16.54\%) of which from Selcuk University, 68 (17.30\%) from Usak University, 62 (15.78\%) from Ankara University, 66 (16.79\%) from Mehmet Akif Ersoy University, 64 (16.28\%) of which from Cukurova University and 68 (17.30\%) from Mugla University participated in the study. In order to collect the study data, the 1st, 2nd, 3rd and 4th grade students in the sample group who had been previously determined randomly were informed about the times when the scales would be applied. Then, the "Self-compassion Scale" was applied on the determined times. Prior to the application, the instructions for the scales were read to the participating students, they were informed about the application and the questions from the students were answered. The applications took about 20 minutes. No problem was encountered during the applications. The required permissions for the study were also obtained from the Ethical Committee of the Usak University.

\subsection{Self-Compassion Scale}

The original Self-compassion Scale is composed of 6 sub-scales and 26 entries. The respondents are requested to rank the frequency of their action regarding the situation stated on a 5-point Likert-type scale ranging from "Almost never $=1$ " to "Almost always $=5 "$. The reliability and validity study for the Turkish version of the Self-compassion scale developed by Neff (2003b) was conducted by Deniz et al. The self-compassion levels were determined in three categories, namely the low, medium and high, by taking into consideration the average and the standard deviation of the scores the students got from the Self-compassion Scale. The average of the scores the students got from the Self-compassion Scale was found to be 70.98 and the standard deviation to be 11.08 . The 

Sport Sciences Faculties of Universities

point which is one standard deviation lower than the average score represents the low self-compassion, while the point one standard deviation higher represents the high self-compassion. In this case, the points lower than 65 are defined as low, the ones between 66 and 90 as medium and the ones over 91 as high self-compassion levels [7].

\section{Data Analysis}

The SPSS 13.0 statistics program was used in the analysis of the data obtained. The frequency (f) test was used in determining the demographical characteristics of the participating students, the arithmetic mean method in determining the levels of their self-compassion, and the Independent Samples t-test and the one-way ANOVA test were used in determining whether their self-compassion levels vary depending on the university and department they study in, their gender, their branch in sports and the province they live in. the significance level was found to be 0.05 .

\section{Results}

As for the demographical information about the students of the Faculties of Sports Sciences, it can be seen that the number of the students studying in the Department of Teaching is 164 (41.79\%), the number of those studying in the Department of Sports management is 133 (33.84\%), and the number of those studying in the Department of Coaching training is $96(24.43 \%)$. Of all participating students, 233 (59.29\%) are male and $160(40.71 \%)$ female. Of the participants of the study, $109(27.74 \%)$ perform Soccer, 48 (12.21\%) with Track and Field, 27 (6.87\%) with Wrestling and $39(9.92 \%)$ with Volleyball. The number of the participants from the province of Konya is $65(16.54 \%)$, from Usak 68 (17.30\%), from Ankara 62 (15.78\%), from Burdur 66 (16.79\%), from Adana $64(16.28 \%)$ and from Mugla $68(17.30 \%)$. Of the participants, $112(28.50 \%)$ are amateur athletes, 9 (2.29\%) professional athletes, $17(4.33 \%)$ from National Teams, 7 (1.78\%) from the Super League, 4 $(1.02 \%)$ from the 2 nd League and $3(0.76 \%)$ from the 3rd League (Table 1).

The average score in regard to the self-compassion levels of the students was found to be $\mathrm{x}=70.98$. The score obtained based on the evaluations shows that the

Table 1 The demographical characteristics of the study group.

\begin{tabular}{llll}
\hline Variable & Parameter & $\mathrm{N}$ & $\%$ \\
\hline Department & Teaching & 164 & 41.73 \\
& Sports management & 133 & 33.84 \\
Gender & Coaching & 96 & 24.43 \\
& Male & 233 & 59.29 \\
Sports branch & Female & 160 & 40.71 \\
& Soccer & 109 & 27.74 \\
& Track and field & 48 & 12.21 \\
The city of residence & Wrestling & 27 & 6.87 \\
& Volleyball & 39 & 9.92 \\
& Konya & 65 & 16.54 \\
& Usak & 68 & 17.30 \\
Team level & Ankara & 62 & 15.78 \\
& Burdur & 66 & 16.79 \\
& Adana & 64 & 16.28 \\
& Mugla & 68 & 17.30 \\
& Amateur & 112 & 28.50 \\
& Professional & 9 & 2.29 \\
& National team & 17 & 4.33 \\
& Super League & 7 & 1.78 \\
& 2nd League & 4 & 1.02 \\
& 3rd League & 3 & 0.76 \\
\hline
\end{tabular}


self-compassion levels of the students in regard to their behaviors in the face of problems were at the medium level (Table 2).

When the differences in the self-compassion levels of the students were examined based on the universities they study in, it was determined that the self-compassion levels of the students from Mugla University were significantly higher than those of the students from Ankara University $(P<0.05)$. No difference was found among other departments $(P>$ $0.05)$.

When the self-compassion levels of the students were examined based on the departments they study in, it was determined that the self-compassion levels of the students studying in the department of Teaching were significantly higher than those of the students studying in the department of Coaching $(P<0.05)$.
When the self-compassion levels of the students were examined based on the sports branches they perform, it was determined that the self-compassion of the students performing soccer were significantly higher than those of the students performing volleyball $(P<0.05)$. The answers given by the student group answering the self-compassion scale for the variable of sports branch showed that there were many sports branches these students performed. In order to make it easier to analyze and interpret the data, the first four sports branches (soccer, track and field, wrestling and volleyball) having most students were taken into consideration and the analysis was conducted accordingly.

When the self-compassion levels of the students examined based on the province the students lived in, it was determined that the self-compassion level of the

Table 2 The self-compassion levels of the group in the face of the problems they experience.

\begin{tabular}{llllll}
\hline & $\mathrm{N}$ & Minimum & Maximum & Average & SD \\
\hline Total score & 393 & 38 & 110 & 70.98 & 11.08 \\
\hline
\end{tabular}

Table 3 Evaluation of the self-compassion levels by the university of the participants.

\begin{tabular}{llllll}
\hline University & $\mathrm{N}$ & Average & SD & Difference & $P$ \\
\hline Selcuk University & 65 & 71.51 & 11.25 & $\mathrm{AB}$ & \\
Usak University & 68 & 72.19 & 10.27 & $\mathrm{AB}$ & \\
Ankara University & 62 & 68.21 & 9.59 & $\mathrm{~A}$ & 0.017 \\
M.Akif Ersoy University & 66 & 70.15 & 11.33 & $\mathrm{AB}$ & \\
Cukurova University & 64 & 69.08 & 10.06 & $\mathrm{AB}$ & \\
Mugla University & 68 & 74.41 & 12.82 & $\mathrm{~B}$ & \\
\hline
\end{tabular}

A, B: Means with different superscripted letters in the same column have statistical significance $(P<0.05)$.

Table 4 Evaluation of the self-compassion levels depending on the departments where the students study.

\begin{tabular}{llllll}
\hline Department & N & Average & SD & Difference & $P$ \\
\hline Teaching & 164 & 72.49 & 10.89 & A & \\
Sports management & 133 & 70.62 & 10.76 & AB & 0.032 \\
Coaching & 96 & 68.92 & 11.59 & B & \\
\hline
\end{tabular}

A, B: Means with different superscripted letters in the same column have statistical significance $(P<0.05)$.

Table 5 Evaluation of the self-compassion levels depending on the sports branches the students perform.

\begin{tabular}{llllll}
\hline Sports branch & $\mathrm{N}$ & Average & SD & Difference & $P$ \\
\hline Soccer & 109 & 72.44 & 10.88 & A & \\
Track and field & 48 & 70.81 & 11.04 & AB & 0.009 \\
Wrestling & 27 & 72.85 & 11.61 & AB & \\
Volleyball & 39 & 66.05 & 9.56 & B & \\
\hline A
\end{tabular}

A, B: Means with different superscripted letters in the same column have statistical significance $(P<0.05)$. 

Sport Sciences Faculties of Universities

Table 6 Evaluation of the self-compassion levels depending on the city of residence.

\begin{tabular}{|c|c|c|c|c|c|}
\hline City of residence & $\mathrm{N}$ & Average & $\mathrm{SD}$ & Difference & $P$ \\
\hline Konya & 65 & 71.51 & 11.25 & $\mathrm{AB}$ & \multirow{6}{*}{0.017} \\
\hline Usak & 68 & 72.19 & 10.27 & $\mathrm{AB}$ & \\
\hline Ankara & 62 & 68.21 & 9.59 & A & \\
\hline Burdur & 66 & 70.15 & 11.33 & $\mathrm{AB}$ & \\
\hline Adana & 64 & 69.08 & 10.06 & $\mathrm{AB}$ & \\
\hline Mugla & 68 & 74.41 & 12.82 & $\mathrm{~B}$ & \\
\hline
\end{tabular}

A, B: Means with different superscripted letters in the same column have statistical significance $(P<0.05)$.

students living in the province of Mugla was significantly higher comparing to the self-compassion level of the students living in Ankara $(P<0.05)$.

\section{Discussion and Conclusions}

Exercise and sports help individuals to gain skills which allow them to develop themselves in terms of personal traits such as the sense of need, demanding, well-being and recognition. Besides developing the social aspects of individuals, various exercise activities brings about differences between the individuals performing sports and the ones who do not in terms of social recognition as well [8]. In the present study, when the self-compassion levels of the students studying in the faculties of sports sciences were examined based on a number of variables, it was determined that they had a medium level of self-compassion; that the self-compassion levels of the students studying in Mugla University were significantly higher than those of the students studying in Ankara University $(P<0.05$; Table 4$)$; that the self-compassion levels of the students studying in the department of Teaching were higher than those of the students studying in the department of Coaching $(P<$ 0.05; Table 4); that the self-compassion levels of the students performing the branch of football were significantly higher than those of the students performing the branch of volleyball $(P<0.05$; Table 5); and that the self-compassion levels of the students living in the province of Mugla were significantly higher than those of the students living in the province of Ankara $(P<0.05$; Tables 3 and 6$)$. The studies conducted on the self-compassion have suggested that mutual sharing is the most important dimension of the study. Besides conserving their own culture, these individuals show respect to other cultures as well. While believing in the basic democratic values such as equality, liberty and justice, they are tolerant both to themselves and to other people [9-14]. Leary et al. suggested that although self-compassion could prevent individuals from performing negative behaviors and attitudes, it was not certainly clear for them what were negative behaviors and attitudes [15]. Researchers suggested that self-compassion emerges as a result of the patterns the individuals introject, their egos, their social physique anxiety or compulsory exercise. The motivation or ego objectives we introject can be extremely prolific. In addition, this study also suggested that the motivation, the ego objectives, the social physique anxiety and the compulsory exercise correlated with less well-being as well, which are of importance in terms of being in parallel with the findings of the present study $[16,17]$.

When the findings were considered together, it was determined that the self-compassion levels of the students studying in various departments of the faculties of sports sciences were medium, and that their city of residence, their department and the sports branch they perform had an effect on their levels of self-compassion (Table 2). Increasing the self-compassion of individuals is of considerable importance in terms of improving their life satisfaction. Thus, adoption of approaches which can increase the feeling of self-compassion in the education, training and exercise activities intended for individuals can affect their lives in a positive way. 

Sport Sciences Faculties of Universities

\section{References}

[1] Neff, K. D. 2003. "The Development and Validation of a Scale to Measure Self-compassion." Self and Identity 2 (3): $223-50$.

[2] Iskender, M. 2009. "The Relationship between Self-compassion, Self-efficacy and Control Belief about Learning in Turkish University Students." Social Behavior and Personality 37 (5): 711-20.

[3] Duatepe, A., and Cilesiz, S. "Development of a Mathematics Attitude Scale." Hacettepe University Journal of Education 16 (17): 45-52. (in Turkish)

[4] Hassandra, M., Goudas, M., and Chroni, S. 2003. "Examining Factors Associated with Intrinsic Motivation in Physical Education, A Qualitative Approach." Psychology of Sport and Exercise 4: 211-23.

[5] Korkmaz, N. H. 2007. "Relationship between Children's Self-esteem in Summer Sports School." Uludag University Faculty of Education XX (1): 49-65. (in Turkish)

[6] Neff, K. D., and MgGehee, P. 2010. "Self-compassion and Psychological Resilience among Adolescents and Young Adults." Self and Identity 9 (3): 225-40.

[7] Deniz, M. E., Kesici, S., and Sumer, A. S. 2008. "The Validity and Reliability Study of the Turkish Version of Self-Compassion Scale." Social Behavior and Personality: An International Journal 36 (9): 1151-60.

[8] Salokun, S. O. 1990. "Effects of Training in Basketball and Field-hockey Skills on Self-concept of Nigerian Adolescent." International Journal of Sport Psychology 21 (2): 121-37.

[9] Neff, K. D. 2001. "Judgments of Personal Autonomy and Interpersonal Responsibility in the Context of Indian Spousal Relationships: An Examination of Young People's Reasoning in Mysore, India." British Journal of Developmental Psychology 19 (2): 233-57.
[10] Neff, K. D., and Harter, S. 2002a. "The Authenticity of Conflict Resolutions among Adult Couples: Does Women's Other-oriented Behavior Reflect Their True Selves?" Sex Roles 47 (9/10): 403-17.

[11] Neff, K. D., and Harter, S. 2002b. "The Role of Power and Authenticity in Relationship Styles Emphasizing Autonomy, Connectedness, or Mutuality among Adult Couples." Journal of Social and Personal Relationships 19 (6): 835-58.

[12] Neff, K. D., and Helwig, C. C. 2002. "A Constructivist Approach to Understanding the Development of Reasoning about Rights and Authority within Cultural Contexts." Cognitive Development 17 (3/4): 1429-50.

[13] Neff, K. D. 2003b. "The Development and Validation of a Scale to Measure Self-compassion." Self and Identity 2 (3): 223-50.

[14] Neff, K. D., and Harter, S. 2003. "Relationship Styles of Self-focused Autonomy, Other-focused Connectedness, and Mutuality across Multiple Relationship Contexts." Journal of Social and Personal Relationships 20 (1): 81-99.

[15] Leary, M. R., Tate, E. B., Adams, C. E., Allen, A. B., and Hancock, J. 2007. "Self Compassion and Reactions to Unpleasant Self-relevant Events: The İmplications of Treating Oneself Kindly." Journal of Personality and Social Psychology 92 (5): 887-904.

[16] Ackard, D. M., Brehm, B. J., and Steffen, J. J. 2002. "Exercise and Eating Disorders in College-aged Women: Profiling Excessive Exercisers.” Eating Disorders 10 (1): 31-47.

[17] Ryan, R. M., and Deci, E. L. 2000. "Self-determination Theory and the Facilitation of Intrinsic Motivation, Social Development, and Well-being." American Psychologist 55: 68-78. 